\title{
Automating The Improvement Of Service Quality: The TELCO Case
}

Elad Harison, Shenkar College of Engineering and Design, Israel Ofer Barkai, Shamoon College of Engineering, Israel

\begin{abstract}
The case under discussion presents a new and innovative framework for implementing preventive service systems that detect potential service malfunctions, attempt to automatically prevent them and notify customers about the results of these operations. Such automated systems may proactively avert service malfunctions and reduce the volume of customer complaints due to service outages. The presented framework is based on four major stages: continuous detection of service delivery infrastructure and equipment, prevention of identified service failures, notification of customers about service failures and follow-up activities. Telco is a major Israeli telecommunications operator that implemented the preventive service methodology and systems to improve the quality of its services to the satisfaction of its largest customers. The model presented in this paper can be utilized by a broad variety of firms and service providers as means for improving the quality of their services, the satisfaction and the loyalty of customers and the ability to retain them for longer periods in an increasingly competitive environment.
\end{abstract}

Keywords: Preventive Service Management; Automated Service Recovery; Service Failures; Customer Complaints; Customer Satisfaction

\section{ORGANIZATION BACKGROUND}

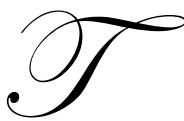

elco is one of the largest telecommunication companies in Israel. The company provides various types of services (such as telephone lines, broadband networks, VoIP and data transmission) to over 2.4 million business and private customers.

The major share of Telco's revenues is generated from local and international calls. Although the company dominates these markets, it aspires to develop its operations and strengthen its position in "newer" telecommunication sectors, such as Internet access and cable TV. The company has a stable balance of operating cash flow that exceeds 5 billion dollars and dedicates substantial shares of it to develop a sophisticated telecommunications network to provide access to advanced services to private and business customers. The network fully operates on digital transmission of voice and data. It consists of approximately 2.8 million access lines and more than $25,000 \mathrm{~km}$ of optical fiber, enabling businesses and households access to broadband Internet via ADSL connections. In addition to these services, Telco's subsidiary firms consist of a large cellular operator with over 2 million subscribers (among them over 50\% subscribe to the latest 3rd generation services), hosting and data communication security solutions, satellite and interactive television channels and outsourcing services for call centers.

The company's organizational structure is based on financial, commercial, operational and engineering divisions, inter alia (see Figure 1). Telco diversifies the management of its operations and activities between the private and business market segments, due to the differences in the needs of both types of customers.

The services provided by Telco are subject to faults and outages that usually affect their end-users. The service support center of the firm receives approximately on average 270000 calls from business sector customers per month. Service representatives can monitor the customer's telephone line by sending an electronic signal over the line that indicates whether the line is faulty or not. If the return signal is defective, the problem is analyzed by 
the monitoring information system and the fault report is passed on to the appropriate technical department. The firm operates different departments that handle various segments of the services and the infrastructure, such as telephone exchange maintenance, telephone line maintenance, and backbone cable maintenance.

The different departments handle about 70 thousand faults per month. On average, there are 28.97 monthly faults for every thousand lines. The rate of repeating faults on the same equipment is approximately $6.5 \%$.

This service division of the firm consists of a service support center, technical support teams for repairing faulty equipment and a computer system that supports the fault identification and handling process. The service operating zone is divided into several geographical units, where each geographical area is assigned with its own technical support team.

The top percentile of the firm's customer base consists of "VIP customers" that generate $45 \%$ of its income from the business sector. Since the uptime of lines of these customers directly affects Telco's earnings, the company prioritizes handling service faults in their infrastructure.

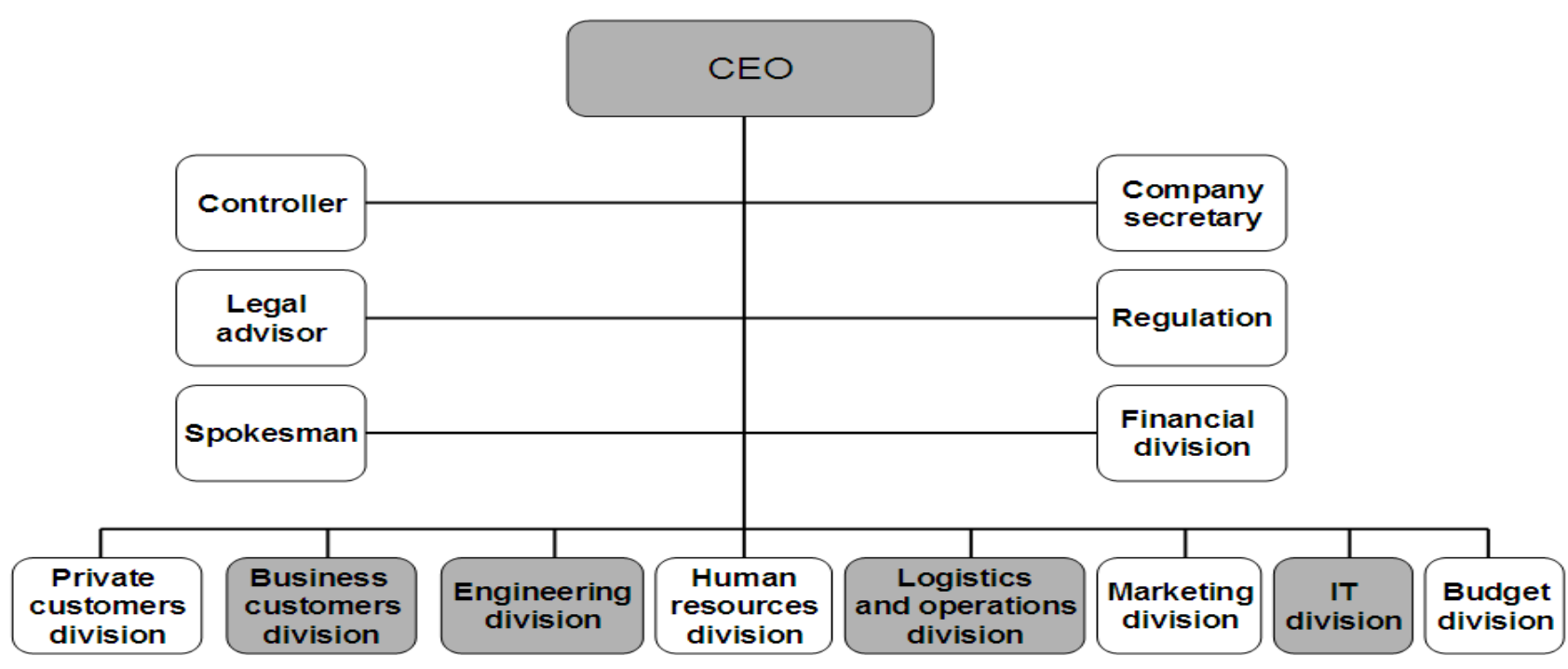

Figure 1: Telco's organizational structure (Divisions and units participating in the Preventive Service Management process are marked in grey)

\section{SETTING THE STAGE}

The dramatic growth of service sectors and companies worldwide and the important role that services play in the operations of firms highlight their major economic and commercial significance. Yet, the provision of services is challenging and requires complex systems and organizations.

The main challenges associated with the provision of services result from their essential attributes, such as high degree of complexity of operations, establishment of interfaces between customers and providers and dynamic allocation of resources, and from the vast diversity in the population of service customers and their needs. Thereby, service providers usually allocate major shares of their resources and establish sets of procedures and interfaces to customers (such as call centers, websites and online chat) to satisfy various consumers with diverse needs. However, at the same time, service providers should strike a balance between costly expenditures on human and technical resources that aim at elevating the satisfaction of customers and the profits that they are able to attract from more satisfied consumers. Nonetheless, despite vast investments in their service infrastructure and operations, service providers often experience dissatisfaction among their customers that results from technical problems and service 
outages. These occurrences may affect the quality of the services perceived by customers, reputation of the service provider, the degrees of trust and loyalty among customers and may result in loss of market shares and income (Duffy et al., 2006). Moreover, the duration of customer-firm relations largely depends on customer satisfaction and influenced particularly by the frequency of service outages. As a result, the revenues of firms that charge their customers on a periodic basis depend on the period of service provision (such as subscription fees or annual fees) and they are motivated to prevent the occurrence of service outages that may affect the propensity of their clients to extend their contracts with them (Bolton, 1998; Zeithaml, 2000; Gupta et al., 2006).

Studies on the operation and management of services emphasize the importance of customer complaint management and its application as means for improving customer satisfaction. Research literature and anecdotal evidence clearly indicate that customer satisfaction the value of services for customers and quality of the services perceived by them decrease when the number of service outages increases (Anderson et al., 1994; Rust et al., 1995; Loveman, 1998; Gupta \& Zeithaml, 2006). In the long run, the revenues of service providers would decrease when customers experience repetitive problems and outages in the services that they use (Johnston, 2001). Therefore, service providers operate complaint management units, ombudsmen and customer relation departments that enable them to correct dissatisfying activities and offer compensation to customers. However, despite the availability of these correction and compensation mechanisms, many customers hesitate to contact them and leave their service providers without expressing their discomfort (Chebat et al., 2005; Zourrig et al., 2009; Sharma et al., 2010).

Service providers particularly emphasize the role of complaint management as a "safety mechanism" that corrects the dysfunctional elements of their services and compensates customers for their damages. However, complaint management is aimed at minimizing dissatisfaction and financial loss after service failures occur (Roth \& Menor, 2003; Rust \& Miu, 2006; Chesbrough \& Spohrer, 2006).

The prevention of faults is a well known concept, particularly in the fields of logistics, maintenance and reliability (Luo \& Bhattacharya, 2006). However, service research has typically overlooked the possibilities of applying tools for preventing service faults, with the exception of healthcare studies (Tucker \& Edmonson, 2003). The elimination of faults and malfunctions in the delivery of services can improve the quality of services and the satisfaction of customers and reduce the costs of complaint management, compensation and service-related damages. These goals can be accomplished by implementing a framework of organizational and technological systems that monitor various operations of the firm that are closely associated with the quality of its services (such as a communications infrastructure or a fiber-optic network).

The importance of preventing dissatisfying provision of services by applying defensive marketing strategies is emphasized by Fornell \& Wernerfelt (1987). These strategies aim at preventing brand switching and customer turnover by proactively protecting services and markets. Firms can do so by effectively addressing the complaints of customers and learning from them about failures in services and operations that can be treated and eliminated.

Interestingly, many service providers do not invest in operating preventive service activities that eliminate part of the service outages and, at the same time, can substantially reduce their expenditure on complaint management units. The preventive service methodology is based on implementation of automated systems and procedures for monitoring the service provision infrastructure to prevent outages and malfunctions in the delivery of services to clients.

Monitoring the processes and systems that are related to the provision of services is particularly important when the demand for services is high (Rust \& Chung, 2006). During these periods, the resources of the service provider are fully employed and the firm risks either service shortages or outages as a result of utilizing them beyond their maximal capability, as in the case of blackouts in electricity grids. At the same time, high demand periods are the most profitable for the firm (Radas \& Shugan, 1998). Therefore, by applying preventive service systems, providers can control their resources to avoid service malfunctions, without lowering the demand for services as long as they do not risk potential failure of their service delivery infrastructure. 


\section{CASE DESCRIPTION}

Mr. Cohen, VP of customer relations in Telco entered the board of directors meeting bearing some bad news: 5 significant customers abandoned the company in the past month.

Following Mr. Cohen's inquiry with the customers it transpired that customers were harmed operationally and economically due to outages in telephony services. Due to these outages customers sustained significant damages that included loss of income of sales in call centers, inability to communicate with company branches in Israel and overseas as well as inability to communicate with the company that resulted in damage to the company's reputation and the cancelation of a large transaction on behalf of one of the customers. The inquiry also revealed that damage to the communication lines of 3 of the 5 customers derived from preventive maintenance works that were carried out in the network. Nonetheless customers were not informed as to the works, which could have prevented the damages if customers had been prepared in advance. VP of customer relations estimated that the annual damage as a result of the loss of the customers amounted to more than $\$ 4.2$ million dollars.

Mr. Levy, the company chief operation officer, proposed to examine the development and implementation of a computerized system of customer notification that would be integrated in the existing call centers of the company. The system would address and handle unplanned malfunctions and service outages that are known in advance so that customers turn to alternative means for the period of outage.

For example, one of the customers is a bank that encountered problems to update its records (for example, withdrawals from ATM machines reported by the communications network; telephone calls made by bank clients; damage to current operations of credit cards and e-wallets that are based upon communication networks). As a result of the outage the bank suffered operational and financial losses that derive from unsatisfied customers who left the bank, loss of income generated by commissions, payment system and inability to execute transactions that could have significantly increased the bank revenues.

\section{Mr. Gonen, the CEO, accepted Mr. Levy's proposal yet expressed a few reservations:}

A. Taking into account a cost-benefit perspective, does the cost of the development of the system and its integration in the existing service system justifies its operation and advantages in terms of customer retention (cost-benefit analysis)?

B. The operation of the system for the entirety of the population involves ongoing, high and current costs that derive from communication costs and employment of additional workers in the centers.

C. Whether each customer is notified upon the occurrence of a malfunction and/or planned outage or following a certain, minimal period of time so as to prevent recurring calls from the customer concerning minor issues.

D. Whether notification of customers in an initiated manner improves customers' satisfaction or harms the company's image due to immediate receipt of malfunction calls.

E. Whether the service system for important customers be monitored in an initiated manner and how urgent this issue is.

Mr. Gonen instructed that the company should focus on the segment of customers that contributes the highest share of income to the company (according to the Pareto principle stating that a small amount of customers generates most revenues for the company). Mr. Gonen asked that a quantitative analysis be prepared of the extent of customers in relation to the income they generate for the company.

Mr. Gonen instructed VPs of marketing, customer relations, engineering and computers to find an integrated technological solution that would provide an appropriate solution to customer needs and would be primarily based upon the internal system that exists in the company. The issues that the VPs were asked to address following the CEO's decision were:

A. The type of computerized systems that are required.

B. The type of customers to be included in the activity. 
C. The type of notification messages customers will receive.

D. The required links between the systems.

Mr. Cohen mentioned that the company operates a CRM system that is used to keep track of the transaction history of the customers and perform data mining and customer classification according to the extent of their activities. The information that contains the customers' payment history can be used to locate and segment the different customers upon whom preventive service tools will be applied. In addition, Mr. Cohen said that the system contains the details of the contact persons assigned to handle malfunctions on the customers' behalf as well as their contact details which facilitate the immediate implementation of the communication and notification mechanism.

Mr. Levy mentioned that the company operated a system that handles system malfunctions and planned outages. Planned outages are aimed at performing preventive maintenance in the telephone network and they are carried out in areas where the number of malfunctions per 1,000 lines is high, which points to poor maintenance of the telephone network.

In accordance with the work plan it was decided that handling planned outages ought to be performed in a week (through preventive maintenance) in the northern industrial area. This area is occupied by large plants and industrial facilities. Shmuel, who manages customer equipment department, is in charge of performance of preventive maintenance works with his team. Preventive maintenance is carried out by the replacement of parts of the telephone line from the customers' communication cabinet. While replacing the line, some lines are out of service for a limited period of time. Therefore, Telco can notify its customers in advance if the outage is planned or when an unanticipated service malfunction occurs by the establishment of an interface between this system to the preventive service system.

The company acts in light of a few basic principles that include attention to customers from a specific group, definition of the means of communication and assessment of the malfunction time that justifies notification of select customers (even if the customer did not notify the company about the malfunction). The population of customers notified by the company as to system malfunctions and planned outages includes customers whose monthly services consumption is above $\$ 50,000$ a month (according to the records kept in the CRM system). Due to outages in land lines the contact person of the customer cannot be notified as to the malfunction and even in an event of planned outage (for the purpose of preventive maintenance) the company takes a chance and prefers not make use of the land line for that purpose. Therefore it was agreed between the customers and the company that messages pertaining to service outages would be delivered through text messages to the contact person. At the same time, a message is sent to the email address of the contact person in the organization. During events in which the company estimates that outage shall last for a period of time longer than 15 minutes, a message will be sent to the customer. This time period was set following consultation with the customers so as not to deliver recurring messages as to malfunctions for a short period of time while at the same time enable customers to prepare for malfunctions that last longer periods of time.

\section{AUTOMATING SERVICE QUALITY IMPROVEMENT: A MODEL FOR PREVENTIVE SERVICE MANAGEMENT}

The prevention of service malfunctions and outages was highlighted by several studies, which elaborate on the importance of this issue from economic, managerial, marketing and operational perspectives (see, for example, Davidow, 2003; Homburg \& Fürst, 2005). Preventive service systems can be implemented in a wide variety of organizations, services and work procedures and their application is not limited to particular sectors or service firms. The method of preventive service management selected by Telco consists of several stages as follows (see also Figure 2):

- Detection represents the continuous monitoring of the service delivery infrastructure that aims at preventing service malfunctions and outages. Detection processes and policies can be applied to monitoring the technical systems that serve the entire population of customers or a selected group of them. Telco's detection systems include only the top $5 \%$ of its customers. Telco reduces the costs of detection by replacing human labor that monitors the service delivery infrastructure by automated systems. 
- $\quad$ Prevention activities are the set of operations that the system carries out to minimize the risks that may hamper the provision of services. This stage is activated following the detection of harmful levels of activity. For example, if the volume of phone calls transferred via a particular line is close to its maximal capacity, Telco's system re-routes part of the calls to alternative segments of the network.

- If a service outage occurs, either due to planned maintenance or due to service failure, despite the efforts to prevent it, the notification system is activated. The system transmits information about the event to customers that can be affected by it and to a selected group of customers that Telco defined due to the importance of its services to them (for example, banks, hospitals and jewelry shops that base their alarm systems on landlines). Notification of customers is operated even when the service failure can go unnoticed, as in the case of malfunctions that occur after office hours. If the service outage is ongoing, Telco notifies customers about it and often specifies which procedures are carried out to solve it. Alternatively, if the service failure has just been discovered and technical assessment suggests that it will continue for at least half an hour, the company also notifies about the expected duration of the outage.

Telco sends three types of notification messages that correspond to three types of service outages or malfunctions, as follows:

1) If a systematic failure occurs, the following message is sent to customers by SMS and by email:

"Dear customer,

Thank you for notifying us about the fault in your communications equipment. The duration of fixing it will be over 15 minutes. The existing fault is a systematic problem that is located in [line identifier]. You are one of our most important customers and we do every effort to fix it as soon as possible. You will be notified when the problem is solved.

Kind regards, [name] - Service Manager”.

2) When the failure is discovered by Telco before customers identify it and contact the helpdesk, the following message is sent:

"Dear customer,

We identified a fault in your communications equipment in your [line identifier]. We do every effort to fix it as soon as possible. You will be notified when the problem is solved.

Kind regards, [name] - Service Manager”.

3) When maintenance activities are planned, the firm notifies customers in advance by providing the following notice:

"Dear customer,

As a part of Telco's efforts to provide you high quality services, we will carry out maintenance activities. Consequently, our services will not be available on [day] between [hours] in lines/location [line identifiers/location identifier]. You are one of our most important customers and we do every effort to minimize maintenance time and to provide our services as soon as possible.

Kind regards, [name] - Service Manager”.

After fixing the service delivery infrastructure, Telco sends a message about renewing the provision of services.

- $\quad$ Follow-up is the last stage of the preventive service management procedures. During this stage, Telco's helpdesks and customer service units support customers by providing updates regarding the service outage, 
managing complaints and offering alternatives to their communication needs, when possible. After the outage is treated, Telco's head of technical maintenance analyzes the outputs that are received from its technical systems to prevent similar malfunctions in the future.

Preventive service systems can be based either on "passive" communication tools that notify customers who call the helpdesk about service outages. The system can also integrate "active" components, notifying selected population customers about problems in service delivery and planned maintenance, as Telco does. To decide which customers are notified about service outages, Telco utilizes the data within its CRM (Customer Relations Management) system that describe the financial transactions of services that customers use. The customers chosen to be notified in cases of service failure are those who pay more than $\$ 50,000$ per month for Telco's services. Messages are sent when outages are expected to be longer than fifteen minutes. Additionally, the CRM system includes records about the contact persons in each organization or firm that should be notified about ongoing or planned outages.

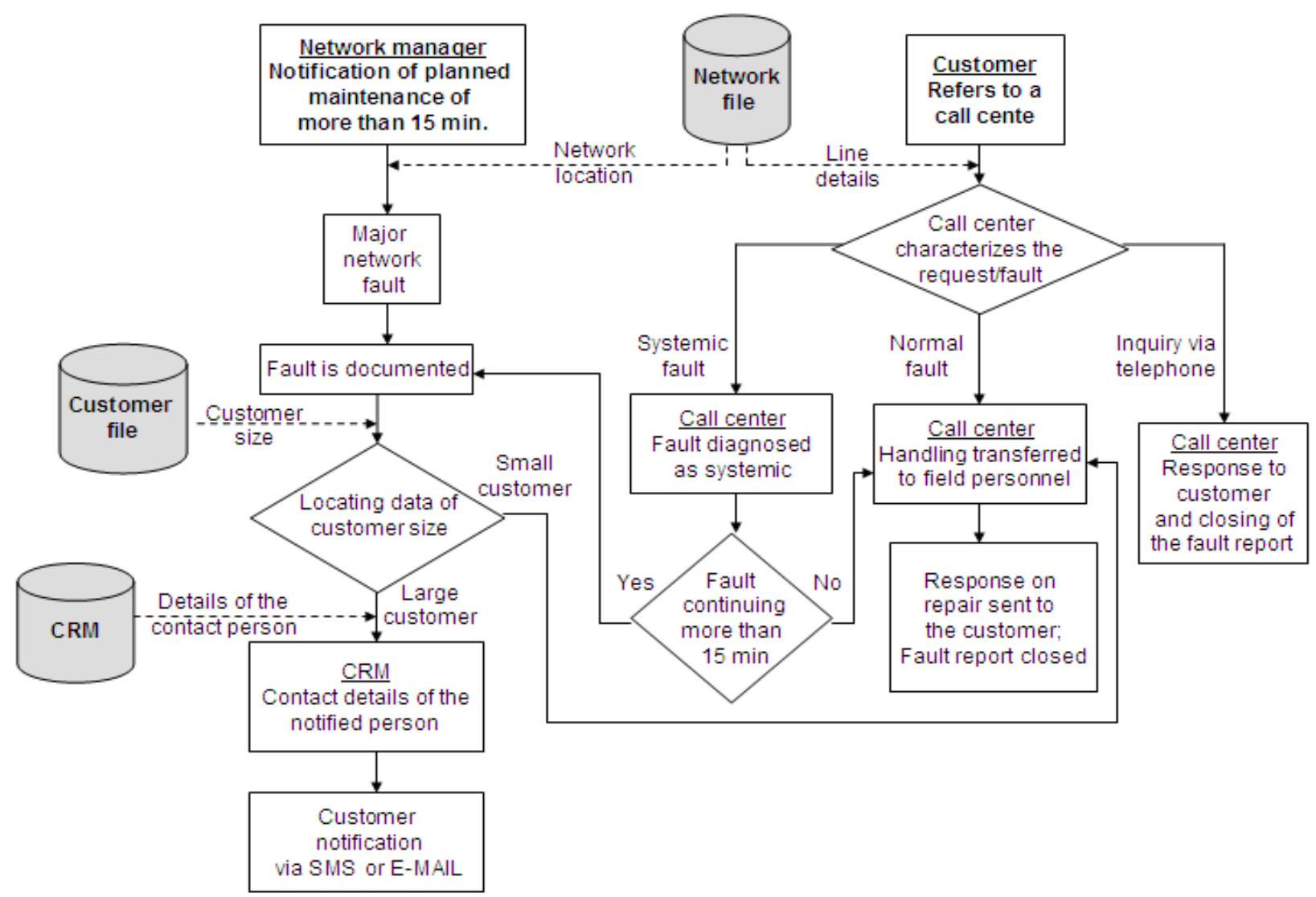

Figure 2: Customer notification processes for preventive maintenance and systemic faults

\section{CONCLUSION}

The Israeli telecommunications market is characterized by an intensifying competition: Entry of new mobile operators, diversity of Internet access platforms (via TV cables, ADSL, wireless networks etc.) and the regulator's agreement to grant mobile virtual network operators (MVNO) licenses may largely affect Telco's dominant position in the market and its revenues (mobile virtual network operators are telecommunications firms that provide services by using the infrastructure of other operators, rather than establishing their own facilities). 
Telco aspires to achieve high level of customer satisfaction. For this purpose, it operates large customer service, helpdesk and complaint management facilities at a substantial cost. Nonetheless, despite the substantial investment in these activities, some of its large customers often abandon the firm in favor of one of its competitors after experiencing long, frequent or acute service outages. The means that Telco offers to resolve service malfunctions in an attempt to assist customers after they have already experienced these events. Yet, part of these problems and the resulting dissatisfaction of customers could have been prevented if the firm had notified customers in advance about expected service outages. In order to improve the quality of its services, Telco applied the preventive service management methodology and implemented automated systems that carry out the different procedures that are included in the detection, prevention, notification and follow-up stages. After a short period since the operation of the preventive service systems, Telco's management realized that customer satisfaction and the quality of the services were improving, while the volume of customer complaints and the number of customers terminating their contracts with the company were continuously decreasing. Telco's management is motivated to further improve these results and it identified the following challenges and issues that are followed by elaboration of the relevant dimensions for addressing them:

- $\quad$ Are there additional situations in which the system can be used to communicate with customers about services that they purchase?

The methodology discussed above can be seen as a starting point for improving the quality of services by application of information systems. However, the systems can be operated in a multitude of processes that require communication with clients, including finance, sales and marketing. Firms should address the following questions: Which elements of the methodology can be utilized to communicate with customers? How can firms use the preventive management methodology as a part of their business strategies and operations?

- How frequent should the detection systems monitor the service delivery infrastructure and equipment?

The detection process can be accomplished almost instantly, covering a selected group of customers every time it is operated. Thereby, monitoring service malfunctions is a repetitive process that can vary between relatively long periods (for example, once in a week or every day) to several milliseconds. The costs of monitoring the service delivery infrastructure increase with frequency, as additional servers are operated and maintained to carry out the growing volume of detection activities. Therefore, firms should facilitate a detection policy that strikes a balance between the quality of the preventive service that it provides to customers and the costs associated with it.

- $\quad$ Should the present group of customers managed by the preventive service systems and processes be expanded or narrowed?

Currently, the selected group of customers that enjoy Telco's preventive service consists of the upper 5\% of the customers by the value of services that they purchase. However, management has doubts whether to extend the group of customers that benefit from this service (and consequently to strengthen their loyalty) or to narrow it due to the additional costs per client. Similar to the issue of the optimal frequency of detecting service malfunctions, Telco should examine the value of the preventive service for other clients, the profits that it derives from them and the impact of the system on their propensity to extend their contract with Telco and to subscribe to new services that it offers.

- Which organizational units should be responsible for the preventive service processes and systems?

The issue is largely affected by the responsibilities of each division that participates in coordinating the application of the preventive service methodology in the organization. Clearly, the organizational unit that leads the process should head the team that implements and operates the preventive service systems and procedures. However, there are many possible configurations for operating the process, which can vary from one phase of the implementation to another. For example, the IT division will be responsible for the development of the detection system, but it will hand over the responsibility for the system to the engineering division once the testing phase will be completed successfully. 
- $\quad$ Can other means of communication to customers and notification messages be used more effectively?

Firms operate email and SMS messages as major means of communications with customers. Yet, these means are "passive", since they notify customers about service malfunctions, but customers cannot respond or communicate with the firms over the same communication channel. Therefore, firms should consider advanced means of communications that can provide additional information to customers. For example, messages delivered via mobile Internet devices can include links that provide more details about ongoing service outages and updated status of the maintenance activities carried out by the service providers to resolve them.

\section{AUTHOR INFORMATION}

Elad Harison, $\mathrm{PhD}$, is a Senior Lecturer at the Department of Industrial Engineering and Management at the Shenkar College of Engineering and Design, Ramat Gan, Israel. He specializes in the Economics of Innovation and technical change in the context of information technologies. He was involved in several research projects on innovation policies and ICT for the European Commission and for several European governments. E-mail: eladha@shenkar.ac.il

Ofer Barkai, $\mathrm{PhD}$, is a Lecturer in the Department of Industrial and Management Engineering at the Shamoon College of Engineering, Be'er Sheva, Israel. In addition he has 27 years of industrial experience. He specializes in wage and compensation strategies at the organizational and managerial levels, compensation schemes, sectorial compensation and payment methods and service organization. E-mail: ofer@sce.ac.il

\section{REFERENCES}

1. Anderson E. W., Fornell C., \& Lehmann D. R. (1994). Customer Satisfaction, Market Share and Profitability. Journal of Marketing, 58, 53-66.

2. Bolton R. N. (1998). A Dynamic Model of the Duration of the Customer's Relationship with a Continuous Service Provider: The Role of Satisfaction. Marketing Science, 17(1), 45-65.

3. Chebat J. C., Davidow M., \& Codjovi I. (2005). Silent Voices: Why Some Dissatisfied Consumers Fail to Complain. Journal of Service Research, 7(4), 328-342.

4. Chesbrough H., \& Spohrer J. (2006). A Research Manifesto for Service Science. Communications of the ACM, 49(7), 35-40.

5. Davidow M. (2003). Organizational Responses to Customer Complaints: What Works and What Doesn't. Journal of Service Research, 5(3), 225-250.

6. Duffy J. A. M., Miller J. M. , \& Bexley J. B. (2006). Banking customers' varied reactions to service recovery strategies. International Journal of Bank Marketing, 24(2), 112-132.

7. Fornell C., \& Wernerfelt B. (1987). Defensive Marketing Strategy by Customer Complaint Management: A Theoretical Analysis. Journal of Marketing Research, 24(4), 337-346.

8. Gupta S., Hanssens D., Hardie B., Kahn W., Kumar V., Lin N., Ravishanker N., \& Sriram S. (2006). Modeling Customer Lifetime Value. Journal of Service Research, 9(2), 139-155.

9. Gupta S., \& Zeithaml V. (2006). Customer Metrics and their Impact on Financial Performance. Marketing Science, 25(6), 718-739.

10. Homburg C., \& Fürst A. (2005). How Organizational Complaint Handling Drives Customer Loyalty: An Analysis of the Mechanistic and the Organic Approach. Journal of Marketing, 69(3), 95-114.

11. Johnston R. (2001). Linking Complaint Management to Profit. Journal of Service Management, 12(1), 6069.

12. Loveman G. W. (1998). Employee Satisfaction, Customer Loyalty and Financial Performance: An Empirical Examination of the Service Profit Chain in Retail Banking. Journal of Service Research, 1(1), 18-31.

13. Luo X., \& Bhattacharya C. B. (2006). Corporate Social Responsibility, Customer Satisfaction, and Market Value. Journal of Marketing, 70(4), 1-18.

14. Radas S., \& Shugan S. M. (1998). Managing Service Demand: Shifting and Bundling. Journal of Service Research, 1(1), 47-64. 
15. Roth A. V., \& Menor L. J. (2003). Insights into Service Operations Management: A Research Agenda. Production and Operations Management, 12(2), 145-164.

16. Rust R. T., Zahorik A. J., \& Keiningham T. L. (1995). Return on Quality (ROQ): Making Service Quality Financially Accountable. Journal of Marketing, 59, 58-70.

17. Rust R. T., \& Miu C. (2006). What Academic Research Tells Us About Service. Communications of the ACM, 49(7), 49-54.

18. Rust R. T., \& Chung T. S. (2006). Marketing Models of Service and Relationships. Marketing Science, 25(6), 560-580.

19. Sharma P., Marshall R., Reday P. A., \& Na W. (2010). Complainers versus non-complainers: a multinational investigation of individual and situational influences on customer complaint behaviour. Journal of Marketing Management, 26(1/2), 163-180.

20. Tucker A. L., Edmondson A. C. (2003). Why hospitals don't learn from failures: Organizational and psychological dynamics that inhibit system change. California Management Review, 45(2), 1-18.

21. Zeithaml V. A. (2000). Service quality, profitability, and the economic worth of customers: What we know and what we need to learn. Journal of the Academy of Marketing Science, 28(1), 67-85.

22. Zourrig H., Chebat J. C., \& Toffoli R. (2009). Consumer revenge behavior: A cross-cultural perspective. Journal of Business Research, 62(10), 995-1001. 